\title{
PYK2 via S6K1 regulates the function of androgen receptors and the growth of prostate cancer cells
}

\author{
Yu-Hsuan Hsiao1,," Yu-Ting Huang1,,", Chia-Yu Hung1, Tzu-Chien Kuo', \\ Fuh-Jinn Luo ${ }^{2}$ and Ta-Chun Yuan' \\ 'Department of Life Science, National Dong Hwa University, Hualien, Taiwan, Republic of China \\ 2Department of Pathology, Mennonite Hospital, Hualien, Taiwan, Republic of China \\ *(Yu-Hsuan Hsiao and Yu-Ting Huang contributed equally to this work)
}

Correspondence should be addressed to Ta-Chun Yuan Email yuan415@mail.ndhu.edu.tw

\begin{abstract}
Androgen receptor (AR) is a steroid hormone receptor that functions as a transcription factor for regulating cell growth and survival. Aberrant AR function becomes a risk factor for promoting the progression of prostate cancer (PCa). In this study, we examined the roles of proline-rich tyrosine kinase 2 (PYK2) and ribosomal S6 kinase 1 (S6K1) in regulating AR expression and activity and growth properties in PCa cells. Compared with normal prostate tissues, PCa tumors exhibited high levels of PYK2 and S6K1 expression. Furthermore, the expression levels of PYK2 and S6K1 were significantly correlated with nuclear AR expression in PCa tissues. We further found the association between PYK2, S6K1, and AR in their protein expression and phosphorylation levels among normal prostate PZ-HPV-7 cells and prostate cancer LNCaP and 22Rv1 cells. Overexpression of the wild-type PYK2 in PZ-HPV-7 and LNCaP cells promoted AR and S6K1 expression and phosphorylation as well as enhanced cell growth. In contrast, expression of the mutated PYK2 or knockdown of PYK2 expression in LNCaP or 22Rv1 cells caused reduced expression or phosphorylation of AR and $\mathrm{S} 6 \mathrm{~K} 1$ as well as retarded cell growth. Under an androgen-deprived condition, PYK2-promoted AR expression and phosphorylation and PSA production in LNCaP cells can be abolished by knocking down S6K1 expression. In summary, our data suggested that PYK2 via S6K1 activation modulated AR function and growth properties in PCa cells. Thus, PYK2 and S6K1 may potentially serve as therapeutic targets for $\mathrm{PCa}$ treatment.
\end{abstract}
Key Words
- prostate cancer
- androgen receptor
- proline-rich tyrosine kinase 2
- ribosomal S6 kinase 1

\section{Introduction}

The androgen receptor (AR) is a steroid hormone receptor that functions as a ligand-regulated transcription factor. In human, the AR is ubiquitously expressed throughout the entire body (Kimura et al. 1993). Upon activation by androgens, cytoplasmic AR dimerizes and translocates into the nucleus where it can bind to androgen-responsive elements (AREs) in the promoter region of target genes, activating gene expression for regulating the growth, differentiation, and survival of AR-expressed cells, such as prostate epithelial cells (Devlin \& Mudryj 2009). However, deregulated AR expression or activity is a key factor to cause the malignant transformation of prostate cancer (PCa) cells. Based on the function of AR in PCa progression, inhibition of AR activity is a therapeutic strategy to treat

Published by Bioscientifica Ltd
Endocrine-Related Cancer (2016) 23, 651-663 
PCa. The functions of AR can be regulated by different mechanisms that modulate the AR transcriptional activity and protein stability. Accumulated evidence indicates that different protein kinases, including MAP kinases, AKT, and PKA, can promote AR transcriptional activity by serine/ threonine phosphorylation (Grossmann et al. 2001). Among the different phosphorylation sites of AR, serine 81 (S81) is the highest stoichiometric phosphorylation site in response to androgens and is critical for enhancing AR functions in nuclear localization, promoter selectivity, and transcriptional activation, thus promoting cell proliferation (Gioeli et al. 2002, Gordon et al. 2010, Chen et al. 2012).

Proline-rich tyrosine kinase 2 (PYK2), also known as RAFTK, CADTK, and CAK- $\beta$, is a nonreceptor protein tyrosine kinase closely related to focal adhesion kinase. PYK2 protein is structurally composed of a central kinase domain flanked by the N-terminal FERM domain and the C-terminal focal adhesion targeting domain (Lev et al. 1995, Mitra et al. 2005). Among four tyrosyl phosphorylation sites, tyrosine (Y) 402 serves as the primary autophosphorylation site that is important for PYK2 and c-Src activation (Li et al. 1999). PYK2 is predominantly expressed in the endothelium, brain, and hematopoietic cells, and sensitive to adhesion-mediated signaling, GPCR activation, stress signals, cytokine stimulation, and the increase of intracellular calcium (Lev et al. 1995, Dikic et al. 1996, Tokiwa et al. 1996, Avraham et al. 2000). In addition to involving the regulation of various physiological functions, PYK2 also plays an oncogenic role in cancer development. In glioma cells, PYK2 regulates cell motility and invasiveness (Lipinski et al. 2005). In hepatocellular carcinoma, PYK2 promotes cell proliferation and invasiveness through c-Src and ERK activation (Sun et al. 2008). In multiple myeloma cells, PYK2 modulates cell proliferation and tumor growth (Zhang et al. 2014). In breast cancer cells, the kinase activity of PYK2 and its Y402 phosphorylation are required for cell invasion (Zrihan-Licht et al. 2000). In PCa cells, PYK2 can mediate ErbB-2 signaling to upregulate the adhesive ability of AR-positive PCa cells (Yuan et al. 2007). PYK2 is also involved in RhoC-promoted invasiveness of PCa cells (Iiizumi et al. 2008). Nevertheless, the role of PYK2 in regulating AR function and PCa cell growth is mostly unknown.

The p70 ribosomal S6 kinase 1 (S6K1), which is encoded by RPS6KB1 gene, belongs to a member of the ribosomal S6 kinase family of serine/threonine kinases (Jeno et al. 1988). Structurally, S6K1 contains two nonidentical kinase domains flanked by the N-terminal and C-terminal regulatory regions. In addition, several serine and threonine residues are important for S6K1 activation. Among the phosphorylation sites of S6K1, phosphorylation of threonine (T) 229 and T389 are most critical for the kinase function. Although S6K1 can be activated by different protein kinases, such as PDK1, AKT and AMPK, the best characterized activator of S6K1 is mammalian target of rapamycin (mTOR) which activates S6K1 by directly phosphorylating it at T389 (Saitoh et al. 2002, Fenton \& Gout 2011). Functionally, S6K1 is known as the major ribosomal protein S6 (RPS6) kinase in mammalian cells and plays an important role in regulating cell size and proliferation (Fingar \& Blenis 2004). Studies suggested the oncogenic role of S6K1 in breast cancer, in which S6K1 is overexpressed in the majority of breast cancer cell lines and primary tumors (Couch et al. 1999, Barlund et al. 2000). A recent study further demonstrates that S6K1 can promote ER $\alpha$ activation by phosphorylating it at S167 in breast cancer cells, leading to increased cell proliferation (Yamnik et al. 2009). Although the functional role of S6K1 in PCa cells is still unclear, the elevated expression or activity of S6K1 is associated with the high-grade PCa tumors in comparison with the noncancerous tissues (Chakraborty et al. 2008, Evren et al. 2010).

In this study, we found that PYK2 and S6K1 were highly expressed in PCa tumors compared with normal prostate issues, and their expression levels were positively correlated with nuclear AR expression. We further showed that PYK2 via S6K1 activation promoted AR expression, S81 phosphorylation, PSA production, and PCa cell proliferation in an androgen-independent fashion. Together, our data suggested the oncogenic role of PYK2 and S6K1 in promoting AR function and PCa cell growth. Thus, PYK2 and S6K1 may potentially serve as therapeutic targets for PCa treatment.

\section{Materials and methods}

\section{Antibodies and chemicals}

The antibodies used for immunoblotting were PYK2, S6K1, AR, PSA, $\beta$-actin (Santa Cruz Biotechnology), p-Tyr402 PYK2, p-Thr389 S6K1 (Cell Signaling), and p-Ser81 AR (Millipore). Horseradish peroxidase (HRP)-conjugated secondary antibodies were obtained from Santa Cruz Biotechnology. PYK2 inhibitor PF-431396, protein synthesis inhibitor cycloheximide ( $\mathrm{CHX})$, proteasome inhibitor MG132, and other chemicals were obtained from Sigma.

Published by Bioscientifica Ltd. 


\section{Cell culture}

Cell culture media and supplements were purchased from Invitrogen. Normal prostate PZ-HPV-7 cells, androgensensitive LNCaP, and androgen-independent 22Rv1 prostate carcinoma cells were purchased from the Biosource Collection and Research Center (BCRC, Hsinchu, Taiwan), which routinely authenticates these lines by short tandem repeat (STR) analysis. All experiments were carried out by each cell line at passages below 30. PZ-HPV-7 cells were cultured in Keratinocyte serum-free medium. LNCaP and 22Rv1 cells were maintained in RPMI-1640 medium supplemented with $5 \%$ fetal bovine serum (FBS), $2 \mathrm{mM}$ glutamine and $0.05 \mathrm{mg} / \mathrm{mL}$ gentamicin.

\section{CDNA expression vector construction and site-directed mutagenesis}

The full-length human PYK2 cDNA carried by the pBluescriptR vector (pBluescriptR-PYK2) was obtained from the BCRC, which served as a template for PCR. The cDNA was amplified using oligonucleotide primers: forward: 5'-GCGATTTAAATTAGCTGCTGCCTGAGAGGAT-3' (SwaI site is underlined) and reverse: 5'-GCGGCGGCCGCGG AAGACCCACATGACCAAC-3' (NotI site is underlined). The PCR products were digested by SwaI/NotI and subsequently ligated with the SwaI/NotI-cut pCDHCMV-MCS-EF1-puro (pCDH) lentiviral vector (System Biosciences, Palo Alto, CA, USA). The ligated products were designated as pCDH-PYK2(WT). To construct the dominant-negative mutants of PYK2 cDNA into a lentiviral expression vector, we performed site-directed mutagenesis to generate two mutants of PYK2, Y402F and K457A. For the PCR, the pBluescriptR-PYK2 plasmid was served as a template and the following oligonucleotides were used as the primers: Y402F forward: 5'-CAGACATC TTCGCAGAGATTCCCGACGAAACCCTGCGAAGGCCC$3^{\prime}$ ' and reverse: 5'-ATCTCTGCGAAGATGTCTGACTCTAT GCTGCAGCTCTCTGAGAG-3'; K457A forward: 5'-TAGC TGTCGCGACCTGCAAGAAAGACTGCACTCTGGACAA CAAG-3' and reverse: 5'-TTGCAGGTCGCGACAGCTACA TTGATTTTCTCCCCTTTATGATT-3' (mutated nucleotides are underlined). The mutagenized PCR fragments were sequenced to confirm the mutations and were then amplified using the same primers that were used for amplifying the wild-type PYK2 cDNA. Subsequently, the mutagenized PCR fragments were digested by SwaI/NotI and ligated with the enzyme-cut pCDH lentiviral vector. The ligated products were designated as pCDH-PYK2(Y402F) and pCDH-PYK2(K457A).

\section{Lentiviral infection}

For expressing the wild-type or mutated PYK2 proteins in PZ-HPV-7 or LNCaP cells, 293FT cells (Invitrogen) were cotransfected with the pCDH vector containing the PYK2 cDNA plus packaging plasmids, using a PolyJet Transfection Reagent (SignaGen Laboratories, Ijamsville, MD, USA). The control cells were cotransfected with the pCDH vector alone plus packaging plasmids. For gene knockdown experiments, lentiviral vectors carrying shRNAs against the PTK2B or RPS6KB1 gene were obtained from the RNAi Core at Academic Sicina (Taipei, Taiwan). For the preparation of the shRNA-containing lentiviruses, 293FT cells were cotransfected with a lentiviral expression vector containing a gene-targeted shRNA and with packaging plasmids. The cells expressing shRNA against genes encoding firefly luciferases or $\beta$-galactosidase served as a control (shCt). After a 48 -h incubation, the culture medium containing lentiviruses was harvested. For infection, cells grown in six-well plates were incubated with viruses in the presence of $8 \mu \mathrm{g} / \mathrm{mL}$ of protamine sulfate and spined at $840 \mathrm{~g}$ for $1 \mathrm{~h}$ at $37^{\circ} \mathrm{C}$. The infected cells were grown for 2 days, and the expression level of PYK2 or S6K1 in these infected cells was detected by Western blotting analysis.

\section{Cell growth assay}

To examine the effects of PYK2 on the growth of PZ-HPV-7 or LNCaP cells, viral-infected cells with a density of $0.7-1 \times 10^{5}$ cells/well were plated on 24 -well plates in a regular medium or a steroid-reduced medium, that is, phenol red-free RPMI-1640 medium supplemented with 5\% charcoal/dextran-treated FBS, $1 \%$ glutamine, and $0.5 \%$ gentamicin. After a 48 -h incubation, one set of attached cells was harvested and counted as day 0 , whereas the remaining cells were fed with fresh medium, and the cell number was counted on day 4 . For shRNA knockdown experiments, viral-infected cells were seeded on 24-well plates. Four-eight hours after incubation, one set of attached cells was harvested and counted as day 0 , whereas the remaining cells were fed with fresh medium. The cells were harvested on day 4 for counting.

\section{Cell lysis and immunoblotting}

Cells were harvested, and the cell lysates were prepared as described previously (Chang et al. 2014). For immunoblotting, an aliquot of total cell lysates in an SDS-PAGE sample buffer was separated by

Published by Bioscientifica Ltd 
electrophoresis and then transferred to a nitrocellulose membrane. After blocking with 5\% nonfat milk or BSA in Tris-buffered saline containing $0.1 \%$ Tween 20 for $1 \mathrm{~h}$ at room temperature (RT), the membrane was incubated with primary antibodies for overnight at $4^{\circ} \mathrm{C}$. After rinsing to remove the excess antibodies, the membrane was incubated with HRP-conjugated secondary antibodies for $1 \mathrm{~h}$ at RT. The specific protein was then detected by an ECL reagent kit (Amersham). The relative level of AR protein was semiquantified by densitometric analysis using ImageJ (NIH).

\section{Tissue microarray and immunohistochemistry}

Prostate cancer tissue arrays containing 17 normal and 80 malignant samples were purchased from US Biomax (\#PR483b; Rockville, MD, USA) and SuperBioChips (\#CA4; Seoul, Korea). The cores on these samples were $1.5-2 \mathrm{~mm}$ in diameter. Immunohistochemistry was performed using a Bond Max Automated Immunostainer and reagents (Leica Biosystems). Briefly, the slides were dewaxed in Bond Dewax solution and hydrated in Bond Wash solution. Antigen retrieval was performed at alkaline $\mathrm{pH}$ using Epitope Retrieval solution 2 (Leica Biosystems) for $20 \mathrm{~min}$ at $100^{\circ} \mathrm{C}$. Subsequently, the slides were incubated with anti-S6K1 (SC-230; Santa Cruz Biotechnology), anti-PYK2 (EP206Y), or anti-AR (EPR1535(2)) antibodies (Abcam) at 1:100 dilution for $30 \mathrm{~min}$. Detection of the antibodies was performed using the Bond Polymer Refine Detection (DS9800) according to manufacturer's protocol. The slides were counterstained with hematoxylin for $2.5 \mathrm{~min}$. The expression of PYK2, $\mathrm{S} 6 \mathrm{~K} 1$, or AR in the prostate epithelia was evaluated using a light microscope, and the scores were divided into three grades: negative $(0)$, low $(1+)$, and high $(2+/ 3+)$. Tumor cores with $>10 \%$ of cells staining $1+$ or greater were defined as positive.

\section{Statistical analysis}

Significance for group comparisons was assessed by Student's two-tailed $t$-test or a one-way ANOVA followed by Dunnett's post hoc comparison. The $\chi^{2}$ test was used for comparison between categorical variables. A $P$ value of $<0.05$ was considered significant. All statistical analyses were performed using Prism 6 (GraphPad Software).

\section{Results}

\section{PYK2 and S6K1 expression are elevated in PCa tissues and associated with nuclear AR expression}

We initially examined the epithelial expression of PYK2 and S6K1 in clinical specimens by immunohistochemical analyses. The representative images showed that none of PYK2 or S6K1 immunoreactivity was found in normal prostate epithelia (Fig. 1A and E). However, PCa tissues displayed differential PYK2 or S6K1 immunoreactivities from negative to high in the cytoplasm of epithelial cells (Fig. 1B, C, D, F, G and H). Table 1 summarizes the intensity data of PYK2 and S6K1 immunostaining in
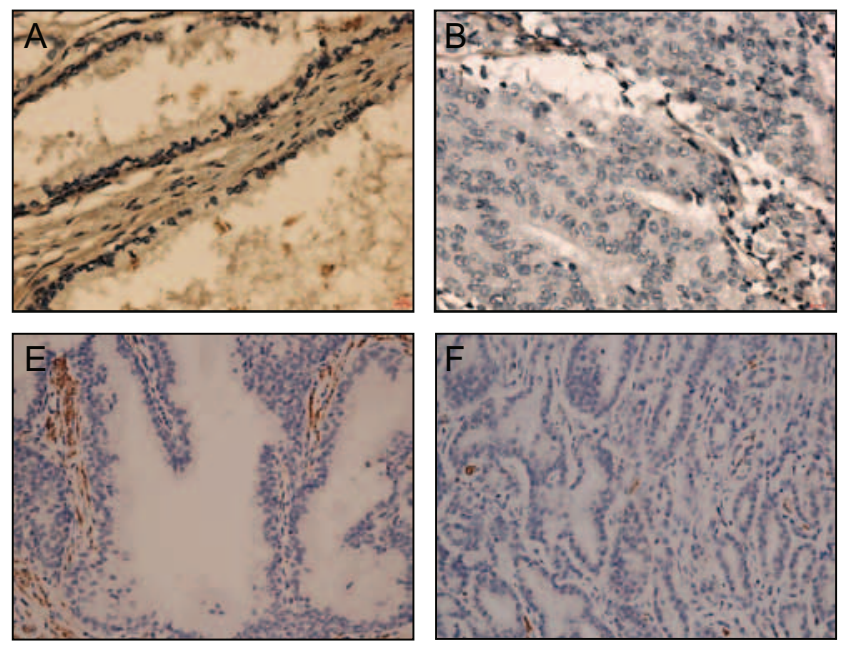
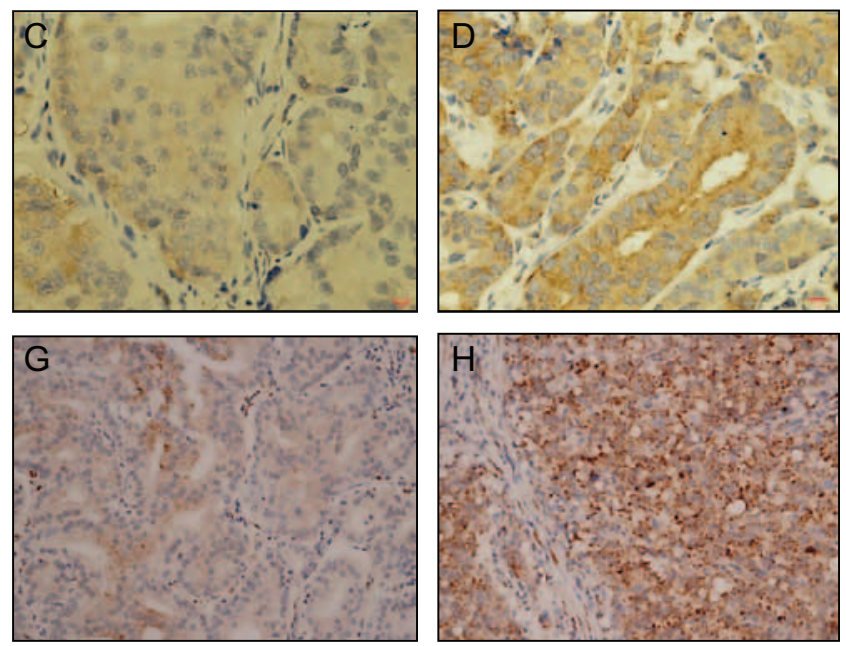

\section{Figure 1}

Immunohistochemical analyses of PYK2 and S6K1 expression in normal and malignant prostate tissues. Representative images showed no PYK2 (A) or S6K1 (E) immunoreactivity in normal prostate epithelia. In prostate cancer tissues, differential immunoreactivities of PYK2 and S6K1 in the epithelia with negative ( $B$ and $F$ ), low ( $C$ and $G)$, or high $(D$ and $H)$ were observed, representatively. Magnification: 400x. Scale bar: $10 \mu \mathrm{m}$. 
Table 1 Expression of PYK2 and S6K1 in normal and malignant prostate epithelia.

\begin{tabular}{|c|c|c|c|c|}
\hline & \multirow[b]{2}{*}{$n(\%)$} & \multicolumn{3}{|c|}{ PYK2 } \\
\hline & & Negative (\%) & Low (\%) & High (\%) \\
\hline Normal & $17(100)$ & $15(88.2)$ & $2(11.8)$ & $0(0)$ \\
\hline \multirow[t]{2}{*}{ Malignant } & $80(100)$ & $54(67.6)$ & $13(16.2)$ & $13(16.2)$ \\
\hline & & & S6K1 & \\
\hline Normal & $17(100)$ & $16(94.1)$ & $1(5.9)$ & $0(0)$ \\
\hline Malignant & $80(100)$ & $54(67.6)$ & $19(23.7)$ & $7(8.7)$ \\
\hline
\end{tabular}

arrayed tissues, including 17 normal and 80 malignant prostate tissues. In the normal tissues, 15 cases $(15 / 17$; $88.2 \%)$ were PYK2 negative and only 2 cases $(2 / 17 ; 11.8 \%)$ showed the positive staining in the epithelia. In PCa tissues, however, $32.4 \%(26 / 80)$ of tissues displayed the PYK2 staining and half of them $(13 / 80,16.2 \%)$ showed a high PYK2 immunoreactivity, despite 67.6\% (54/80) of PCa tissues showing no PYK2 immunoreactivity. Similar to PYK2, the S6K1 immunoreactivity was only found in 1 case $(1 / 17 ; 5.9 \%)$ among 17 normal prostate tissues. In PCa tissues, 19 cases $(19 / 80,23.7 \%)$ and 7 cases $(7 / 80,8.7 \%)$ displayed the low and high S6K1 immunoreactivity, respectively. Despite no significant correlation exhibiting between PYK2 or S6K1 expression and tumor grading or staging, more high-grade tumors expressed a high PYK2 compared with the low-grade tumors (Table 2). We further determined the linkage between PYK2, S6K1, and nuclear AR expression in arrayed PCa tissues. The representative images in Fig. 2 showed the consistency of PYK2, S6K1, and AR immunoreactivities at the corresponding positions in the same tissues. Table 3 summarizes the intensity data of PYK2, S6K1, and nuclear AR staining in 80 PCa tumors and the Chi-squared tests indicate the significant correlation between PYK2 and nuclear AR expression $(P=0.033)$, between S6K1 and AR expression $(P=0.0064)$, and between PYK2 and S6K1 expression $(P=0.0023)$. Taken together, these results suggested that the expression of PYK2 and S6K1 was elevated in PCa tissues and their expression levels were associated with nuclear AR expression.

\section{Correlation between PYK2, S6K1, and AR expression and phosphorylation in prostate cell lines}

To examine whether PYK2 could play a regulatory role in S6K1 and AR functions in PCa cells, we analyzed the expression and phosphorylation levels of PYK2, S6K1, and AR in PZ-HPV-7, a normal prostate cell line, and two PCa cell lines, that is, androgen-sensitive LNCaP cells and androgen-independent 22Rv1 cells. As shown in Fig. 3, under a steroid-reduced condition, PZ-HPV-7 cells expressed very low levels of PYK2 and S6K1, and their phosphorylation levels were less detectable. Although PZ-HPV-7 cells expressed AR, the level of PSA was hardly detected. Compared to PZ-HPV-7 cells, 22Rv1 cells contained relatively high levels of expression or phosphorylation of PYK2, S6K1, AR, and PSA. Among three cell lines, LNCaP cells exhibited the highest levels in the expression or phosphorylation of PYK2, S6K1, AR, and PSA. Similar results were also observed in those cells regarding the protein expression and phosphorylation profiles in the regular condition with androgens (Fig. 3).

Table 2 Associations of PYK2 and S6K1 expression with clinicopathological parameters in 80 prostate cancer patients.

\begin{tabular}{|c|c|c|c|c|c|c|c|c|c|}
\hline \multirow[b]{2}{*}{ Characteristics } & \multirow[b]{2}{*}{ n $(100 \%)$} & \multicolumn{3}{|c|}{ PYK2 } & \multirow[b]{2}{*}{$P$ value } & \multicolumn{3}{|c|}{ S6K1 } & \multirow[b]{2}{*}{$P$ value } \\
\hline & & Negative (\%) & Low $(\%)$ & High (\%) & & Negative (\%) & Low (\%) & High (\%) & \\
\hline Age (mean) & & & & & 0.98 & & & & 0.42 \\
\hline$<66.4$ & 40 & $27(67.5)$ & $7(17.5)$ & $6(15.0)$ & & $25(62.5)$ & $12(30.0 \%)$ & $3(7.5 \%)$ & \\
\hline$>66.4$ & 40 & $27(67.5)$ & $6(15.0)$ & 7 (17.5) & & $29(72.5)$ & $7(17.5 \%)$ & $4(10.0 \%)$ & \\
\hline Gleason score & & & & & 0.70 & & & & 0.25 \\
\hline$<7$ & 18 & $14(77.8)$ & $2(11.1)$ & $2(11.1)$ & & $14(77.8)$ & $4(22.2 \%)$ & $0(0.0 \%)$ & \\
\hline 7 & 24 & $16(66.7)$ & $5(20.8)$ & $3(12.5)$ & & $18(75.0)$ & $3(12.5 \%)$ & $3(12.5 \%)$ & \\
\hline$>7$ & 38 & $24(63.1)$ & $6(15.8)$ & $8(21.1)$ & & $22(57.9)$ & $12(31.6 \%)$ & $4(10.5 \%)$ & \\
\hline Tumor size & & & & & 0.09 & & & & 0.54 \\
\hline $\mathrm{T} 1+\mathrm{T} 2$ & 26 & $21(80.8)$ & $4(15.4)$ & $1(3.8)$ & & $19(73.1)$ & $6(23.1 \%)$ & $1(3.8 \%)$ & \\
\hline $\mathrm{T} 3+\mathrm{T} 4$ & 54 & $33(61.1)$ & $9(16.7)$ & $12(22.2)$ & & $35(64.8)$ & $13(24.1 \%)$ & $6(11.1 \%)$ & \\
\hline Nodal stage & & & & & 0.20 & & & & 0.22 \\
\hline$N=0$ & 59 & $42(71.2)$ & $10(16.9)$ & 7 (11.9) & & 43 (72.9) & $12(20.3 \%)$ & $4(6.8 \%)$ & \\
\hline $\mathrm{N}>0$ & 21 & $12(57.1)$ & $3(14.3)$ & $6(28.6)$ & & $11(52.4)$ & $7(33.3 \%)$ & $3(14.3 \%)$ & \\
\hline Distant metastasis & & & & & 0.61 & & & & 0.88 \\
\hline$M=0$ & 63 & $43(68.2)$ & $11(17.5)$ & $9(14.3)$ & & 43 (68.3) & $15(23.8 \%)$ & $5(7.9 \%)$ & \\
\hline$M>0$ & 17 & $11(64.7)$ & $2(11.8)$ & $4(23.5)$ & & $11(64.7)$ & $4(23.5 \%)$ & $2(11.8 \%)$ & \\
\hline
\end{tabular}


Negative
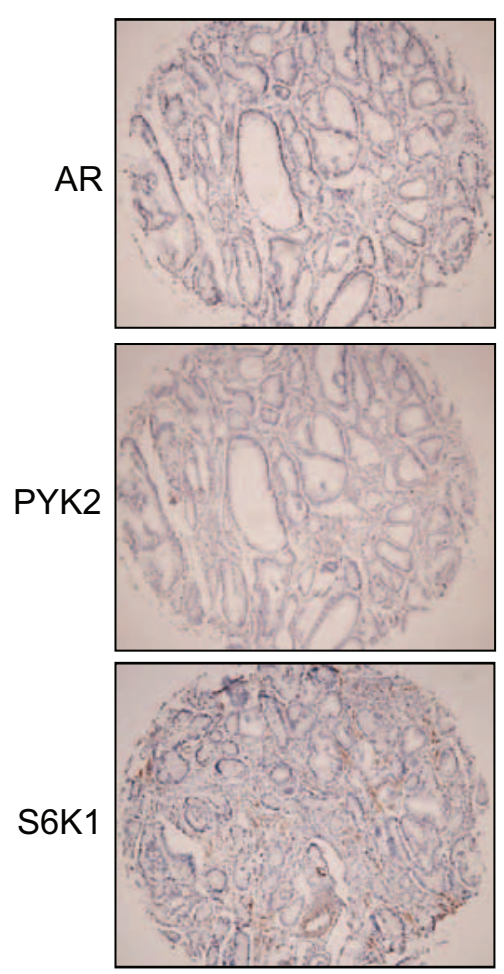

Low
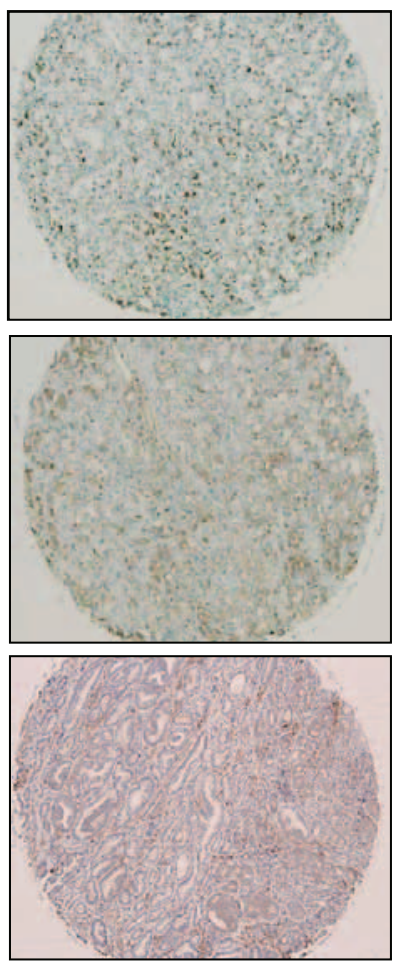

High
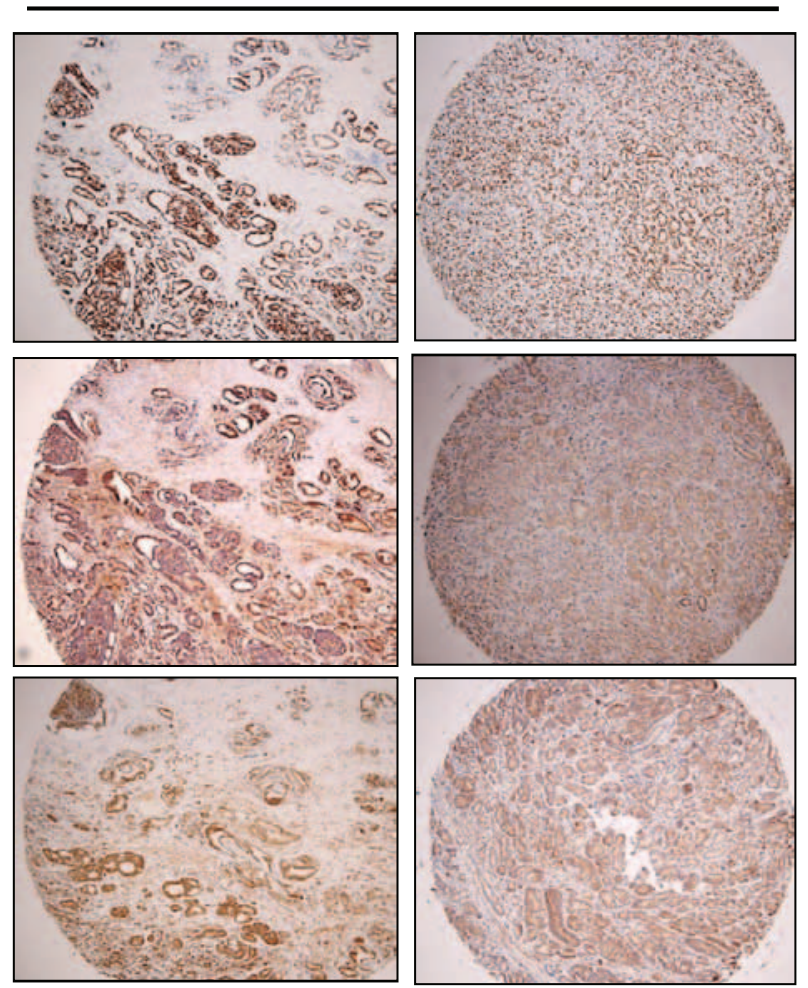

Figure 2

Correlation between PYK2, S6K1, and nuclear AR expression in prostate cancer tissues. Prostate tumors arrayed in a tissue microarray were evaluated for PYK2, S6K1 and nuclear AR expression. Representative images showed the consistency of PYK2, S6K1 and AR immunoreactivities at the corresponding positions in the same tissues. Differential PYK2, S6K1 and nuclear AR immunoreactivities with negative, low or high were observed. Magnification: 100x.

The data collectively suggested the correlation between PYK2, S6K1, and AR in their protein expression and phosphorylation levels in normal and malignant prostate cell lines.

Table 3 Correlation between PYK2, S6K1 and AR in 80 prostate cancer tissues.

\begin{tabular}{|c|c|c|c|c|}
\hline \multirow[b]{2}{*}{ AR } & \multicolumn{3}{|c|}{ PYK2 } & \multirow[b]{2}{*}{$P$ value } \\
\hline & Negative (\%) & Low (\%) & High (\%) & \\
\hline Negative & $14(17.6)$ & $0(0)$ & $1(1.2)$ & 0.033 \\
\hline Low & $9(11.2)$ & $1(1.2)$ & $0(0)$ & \\
\hline \multirow[t]{2}{*}{ High } & $31(38.8)$ & $12(15)$ & $12(15)$ & \\
\hline & & S6K1 & & \\
\hline Negative & $14(17.6)$ & $0(0)$ & $1(1.2)$ & 0.0064 \\
\hline Low & $10(12.5)$ & $0(0)$ & $0(0)$ & \\
\hline \multirow{2}{*}{ High } & 30 (37.5) & $19(23.7)$ & $6(7.5)$ & \\
\hline & & PYK2 & & \\
\hline \multicolumn{5}{|l|}{ S6K1 } \\
\hline Negative & $43(53.7)$ & $7(8.8)$ & $4(5)$ & 0.0023 \\
\hline Low & $7(8.8)$ & $6(7.5)$ & $6(7.5)$ & \\
\hline High & $4(5)$ & $0(0)$ & $3(3.7)$ & \\
\hline
\end{tabular}

PYK2 regulates the expression and phosphorylation of S6K1 and AR and the growth properties of PZ-HPV-7 and LNCaP cells

To examine whether PYK2 can regulate S6K1 and AR expression or phosphorylation in benign and malignant prostate cells, we initially expressed the wild-type PYK2 in PZ-HPV-7 cells. Compared with the vector control cells, overexpressed PYK2 caused itself phosphorylation at Y402 (pY402) and led to the increases in S6K1 and AR expression and phosphorylation (Fig. 4A, left panel). Furthermore, PYK2-overexpressed cells exhibited an enhanced growth rate, approximately 30\% higher than that of the vector control cells (Fig. 4B). Because the pY402 and kinase activity of PYK2 are required for PYK2regulated functions, we next examined the roles of the pY402 and kinase activity of PYK2 in PYK2-regulated S6K1 and AR expression and phosphorylation in LNCaP cells. As shown in the right panel of Fig. 4A, under an androgen-deprived condition, LNCaP cells expressing the wild-type PYK2 exhibited an elevated pY402 level and caused increases in S6K1 and AR expression and

Published by Bioscientifica Ltd 


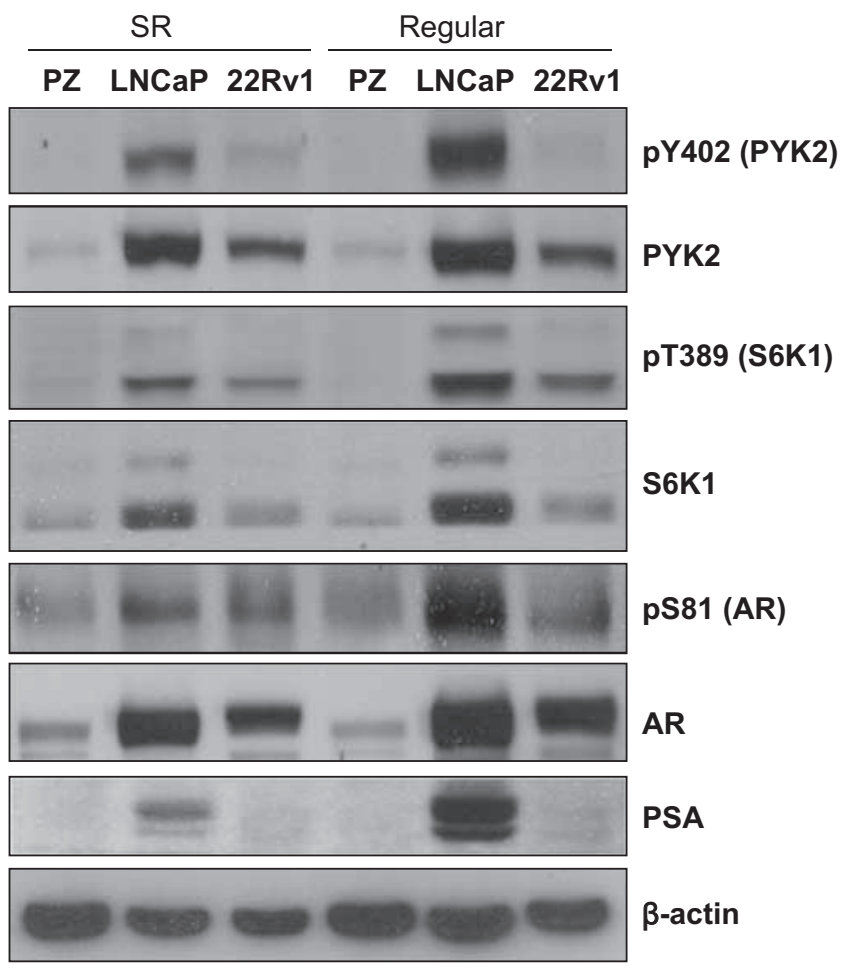

Figure 3

Correlation between PYK2, S6K1 and AR expression and phosphorylation in benign and malignant prostate cell lines. PZ-HPV-7 (PZ), LNCaP and 22Rv1 cells were cultured in a regular medium or in a steroid-reduced (SR) medium, that is, phenol red-free medium supplemented with $5 \%$ charcoal/dextran-treated FBS. Cells were then harvested and total lysates were prepared for immunoblotting with antibodies against the PYK2, S6K1, AR, and PSA proteins, and the levels of phospho-PYK2 at Tyr-402 (pY402), phospho-S6K1 at Thr-389 (pT389), and phospho-AR at Ser-81 (pS81). As a loading control, the level of $\beta$-actin was examined. phosphorylation as well as PSA production. However, overexpression of $\mathrm{Y} 402 \mathrm{~F}$ or $\mathrm{K} 457 \mathrm{~A}$, two dominantnegative mutants of PYK2, in LNCaP cells led to decreases in $\mathrm{S6K1}$ and AR expression and phosphorylation as well as PSA production. Results from the proliferation assays further showed that expression of the wild-type PYK2 in LNCaP cells promoted their androgen-independent growth, whereas expression of the Y402F or K457A mutant inhibited cell growth in the absence of androgens (Fig. 4C). These results collectively suggested that PYK2 enhanced the activities of S6K1 and AR and the growth properties in PZ-HPV-7 and LNCaP cells in the presence or absence of androgens, and its pY402 and kinase activity were required for PYK2-regulated functions.

\section{Suppression of PYK2 expression or activity inhibits the activities of S6K1 and AR in LNCaP and 22Rv1 cells}

We next knocked down PYK2 expression in LNCaP and 22Rv1 cells by expressing PTK2B-targeted shRNAs. As shown in Fig. 5A (left panel), compared with the shCt control cells, the PYK2-knockdown LNCaP cells exhibited a decreased level of PYK2 expression, correlating with reduced levels of S6K1 and AR phosphorylation, AR expression, and PSA production. Similar results were also observed in the PYK2-knockodown 22Rv1 cells (Fig. 5A, right panel). Importantly, the PYK2-knockdown LNCaP or 22Rv1 cells showed the morphological feature of cell shrinkage (Fig. 5B) and exhibited a slow growth rate, nearly 40-50\% lower than that of the shCt control cells (Fig. 5C and D). We further examined the impact of inhibiting the PYK2
A

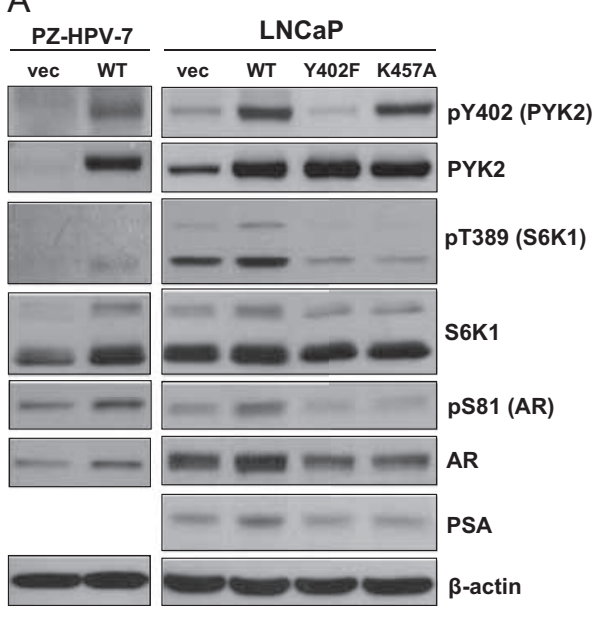

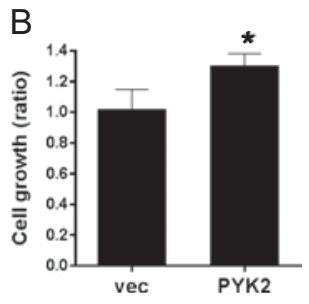

C

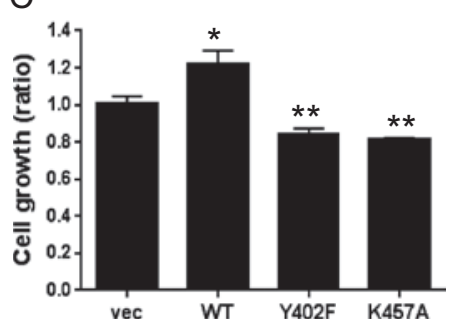

Figure 4

Increased PYK2 expression promotes the expression and phosphorylation of S6K1 and AR and the growth properties in PZ-HPV-7 and LNCaP cells. (A) PZ-HPV-7 and $\mathrm{LNCaP}$ cells were infected with viruses carrying cDNA encoding the wild-type PYK2 (WT) or two mutants, Y402F or K457A. The vector alone expressing cells were served as control cells. Cells were cultured in the steroid-reduced (SR) medium. After 4 days of incubation, cells were harvested for Western blotting analyses. (B) PZ-HPV-7 cells were seeded on 24-well plates and maintained in the regular medium. After a $48 \mathrm{~h}$ of incubation, one set of attached cells was harvested and counted as day 0 , whereas the remaining cells were fed with fresh medium. Cells were then harvested on day 4 for cell counting. (C) LNCaP cells were seeded on 24-well plates and cultured in the SR medium. After a 48-h incubation, one set of attached cells was harvested and counted as day 0 , whereas the remaining cells were then harvested on day 4 for cell counting. Data were expressed as the mean \pm S.D. from three independent experiments. ${ }^{*} P<0.05,{ }^{*} P<0.01$ vs the ratio of vector control cells. 
A

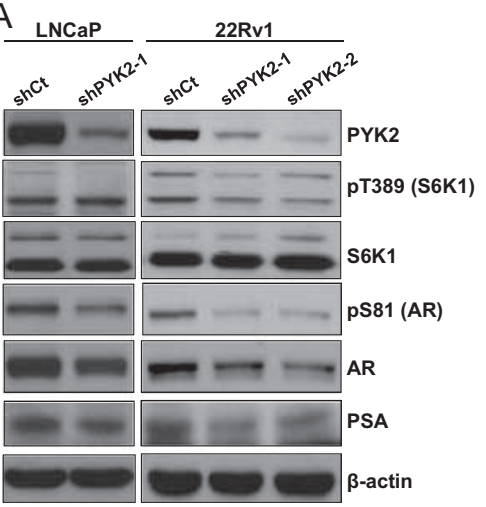

B

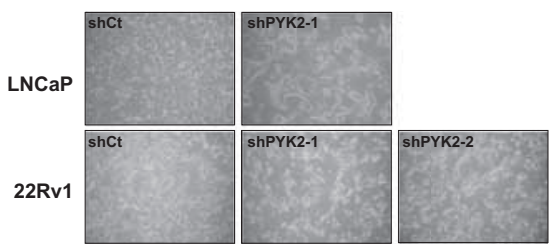

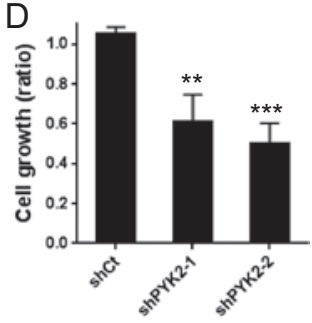

Figure $\mathbf{5}$

Knocking down PYK2 expression or activity causes decreases in the expression and phosphorylation of S6K1 and $A R$ and the growth properties in LNCaP and 22Rv1 cells. (A) LNCaP or 22Rv1 cells were infected with viruses carrying control shRNA (shCt) or PTK2B-targeted shRNA (i.e., shCt, shPYK2-1, or shPYK2-2). Forty-eight hours after infection, cells were then harvested for Western blotting analyses. Alternatively, infected cells were seeded on 24-well plates in a regular medium. After a 48-h incubation, one set of attached cells was harvested and counted as day 0 . On day 4 , (B) the morphological changes of the remaining cells were photographed under the light microscope (magnification: 100x), and the number of (C) LNCaP or (D) 22Rv1 cells was counted. Data were expressed as the mean \pm s.D. from three independent experiments. ${ }^{*} P<0.05, * * P<0.01$, $* * * p<0.001$ vs the ratio of shCt control cells. (E) LNCaP cells were treated with $5 \mu \mathrm{M}$ PF-431396 (PF) for $24 \mathrm{~h}$. The cells treated with an equal volume of solvent (DMSO) served as a vehicle (veh) control. Total lysates were used for Western blotting analyses, and (F) the morphological changes were photographed under the light microscope (magnification: 100x).

activity on S6K1 and AR expression and phosphorylation by treating LNCaP or 22Rv1 cells with PF-431396, a potent pyrimidine-based PYK2 inhibitor (Buckbinder et al. 2007). Compared with the vehicle control cells, treatment of $5 \mu \mathrm{M}$ PF-431396 in LNCaP cells caused decreases in the levels of pY402 and PYK2 expression. Importantly, treatment of $5 \mu \mathrm{M}$ PF-431396 also resulted in remarkable reduction in the expression and phosphorylation of $\mathrm{S} 6 \mathrm{~K} 1$ and $\mathrm{AR}$ as well as PSA production (Fig. 5E, left panel). Similar results were also observed in the PF-431296-treated 22Rv1 cells (Fig. 5E, right panel). The images from morphological analyses also revealed the feature of cell shrinkage after PF-431396 treatment (Fig. 5F). These data further supported the notion that PYK2 expression or activity was

\section{A}

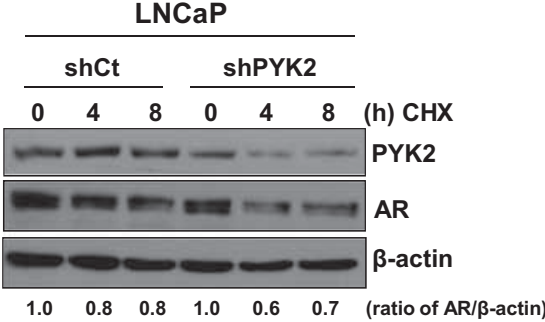

B

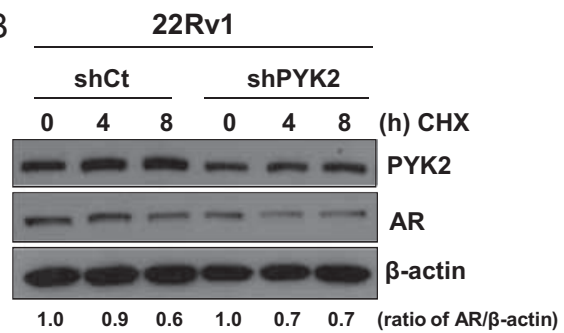

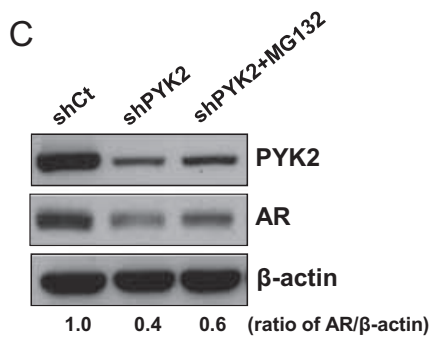

Figure 6

The expression of PYK2 is critical for maintaining the AR protein stability in LNCaP or 22Rv1 cells. (A) LNCaP cells or (B) $22 \mathrm{Rv} 1$ cells infected with viruses carrying the control (shCt) or PTK2B-targeted shRNA (shPYK2). After 2 days of viral infection, cells were treated with $10 \mu \mathrm{g} / \mathrm{mL} \mathrm{CHX}$ for indicated time periods. Cells were then harvested and total lysates were prepared for Western blotting analyses. The expression level of AR was quantified using ImageJ software and the relative expression ratio was normalized to $\beta$-actin level. (C) PYK2-knockdown LNCaP cells were treated with $0.01 \mu$ M MG132 for $48 \mathrm{~h}$. Cells were then harvested and total lysates were prepared for Western blotting analyses. 
A
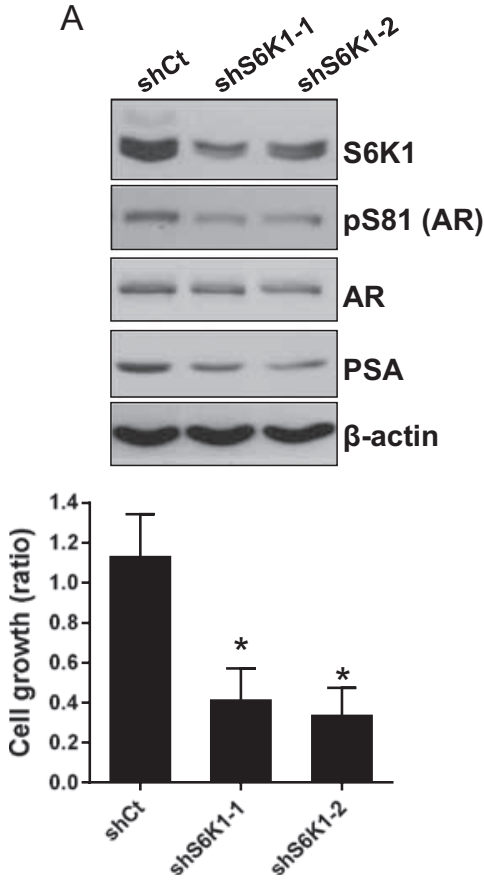

B

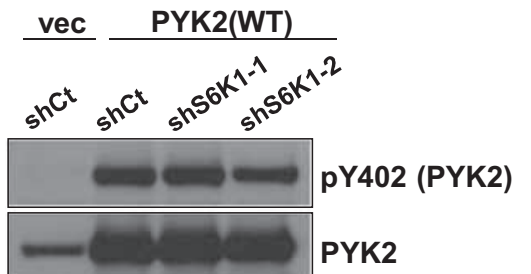

pT389 (S6K1)

S6K1

pS81 (AR)

AR

PSA

$\beta$-actin
Figure 7

S6K1 is required for PYK2-promoted AR function in LNCaP cells in the absence of androgens. (A) LNCaP cells infected with viruses carrying the control (shCt) or RPS6KB1-targeted shRNA (shS6K1-1 or shS6K1-2). After 2 days of viral infection, cells were harvested and total lysates were prepared for Western blotting analyses (upper panel). The infected cells were also seeded into 24 -well plates. After 4 days of culture, the cell growth rate (lower panel) was determined as described in "Materials and methods" section. All the data were expressed as the mean \pm S.D. from three independent experiments. Each set of experiments was conducted in duplicate. ${ }^{*} P<0.05$ vs the ratios of shCt control cells. (B) LNCaP cells stably expressing the vector control or PYK2(WT) plasmid were infected with viruses carrying the control or RPS6KB1-targeted shRNA. After 2 days of viral infection, cells were cultured in the SR medium for 2 days and total cell lysates were prepared for Western blotting analyses. critical for modulating the functions of S6K1 and AR and the growth of PCa cells.

\section{PYK2 promotes AR expression by enhancing its stability}

To determine whether PYK2 is required for maintaining AR protein stability, we examined the effects of $\mathrm{CHX}$, a protein synthesis inhibitor, on AR expression in PYK2knockdown LNCaP cells. As shown in Fig. 6A, PYK2knockdown cells displayed a $40 \%$ decrease in AR protein levels after $4 \mathrm{~h}$ of treatment. However, the shCt control cells only showed a $20 \%$ reduction in AR protein levels after treatment. Similar results were observed in the CHX-treated 22Rv1 cells. After $4 \mathrm{~h}$ of treatment, PYK2knockdown cells exhibited a 30\% decrease in AR protein levels, compared with a 10\% reduction in the shCt control cells (Fig. 6B). We further examined whether PYK2 protects AR from proteasomal degradation by treating PYK2-knockdown cells with the proteasome inhibitor MG132. As shown in Fig. 6C, treatment of MG132 in PYK2-knockdown LNCaP cells led to the restoration of AR protein levels from 40 to $60 \%$, compared with the shCt control cells. The data collectively suggested the function of PYK2 in modulating AR protein stability.

\section{S6K1 is required for PYK2-regulated AR expression and activity in LNCaP cells}

We further determined the role of S6K1 in PYK2regulated AR function. As shown in Fig. 7A (upper panel), knockdown of S6K1 expression in LNCaP cells resulted in diminished AR expression and phosphorylation and reduced PSA production. Furthermore, S6K1depleted LNCaP cells also exhibited a slow growth rate, approximately 60-70\% lower than that in the shCt control cells (Fig. 7A, lower panel). We next examined whether S6K1 is required for PYK2-modulated androgenindependent AR activation. As shown in Fig. 7B, overexpression of PYK2 in LNCaP cells led to increases in S6K1 and AR expression and phosphorylation as well as PSA production under an androgen-depleted condition, similar to the results in Fig. 4C. Importantly, PYK2promoted AR expression and phosphorylation as well as PSA production were abolished by knocking down S6K1 expression (Fig. 7B). These results indicated that S6K1 expression was required for PYK2-regulated AR function in LNCaP cells.

\section{Discussion}

During the initial stage of prostate malignancy, PCa cells require androgens for their growth and survival, but eventually they acquire the androgen-independent phenotype which is refractory to hormonal therapies, causing tumor relapse and cancer-related death (Crawford et al. 1999). Despite aberrant AR expression or activation serving as the primary cause of castrationresistant PCa, its underlying molecular mechanism is not fully understood. In this study, we showed the clinical significance of PYK2 and S6K1 expression in PCa tumors

Published by Bioscientifica Ltd 
and the positive correlation between PYK2, S6K1, and nuclear AR expression in archival PCa specimens. We further demonstrated that PYK2 promoted AR expression and activity in PCa cells, which was mediated by a S6K1dependent mechanism and, in turn, led to androgenindependent growth. To our knowledge, this is the first report showing the oncogenic roles of PYK2 and S6K1 in promoting AR function and PCa cell growth. Thus, PYK2 and S6K1 may potentially serve as therapeutic targets for PCa treatment.

PYK2 is mainly expressed in the central nervous system and hematopoietic cells; however, lines of evidence indicated the elevated expression of PYK2 in malignant tumors of epithelial origin. In hepatocellular carcinoma and nonsmall cell lung cancer, overexpression of PYK2 is found in approximately $60 \%$ of tumors evaluated and is significantly correlated with poor prognosis or lymph node metastasis (Sun et al. 2007, Zhang et al. 2008). In breast and bladder cancers, the expression of PYK2 elevated in malignant lesions compared with benign tissues (Behmoaram et al. 2008, Genua et al. 2012). Our data clearly showed that PYK2 expression was detected in $32.4 \%$ of PCa tumors evaluated and half of them exhibited a high level of expression, whereas few of normal tissues exhibited a weak PYK2 immunoreactivity. Thus, our results supported the notion that PCa tumors, similar to other epithelium-derived cancers, expressed an elevated level of PYK2, higher than that in the benign epithelia.

Stanzione and coworkers first reported the expression of PYK2 in benign and malignant prostate tissues (Stanzione et al. 2001). However, in contrast to our observations, Stanzione's works showed that PYK2 is expressed only in benign prostate tissues, whereas its expression progressively reduces with an increasing grade of malignancy of PCa. This contradictory result may be associated with two differences between our and Stanzione's IHC studies. First, we employed a polymer-based detection system in our study in order for eliminating any problem caused by endogenous biotin, differing from Stanzione's works using avidinbiotin methods. It should be noted that normal tissues exhibit a higher level of endogenous biotin compared with malignant tumors (Ballantyne \& Mchenry 1949, Fahmy et al. 2014). Without effectively blocking biotin, it may lead to data misinterpretation. Second, the PYK2 antibody we used was a commercial product having been tested for IHC. However, the antibody (anti-PYK2 \#600) used in Stanzione's works was previously validated for immunoblotting and immunoprecipitation but not for
IHC. In addition, our study showed that PYK2 was highly expressed in AR-positive PCa cell lines (LNCaP and 22Rv1) compared with the benign prostate cells (PZ-HPV-7), supporting our finding in clinical specimens.

It is well known that AR is expressed in the prostate stroma in addition to the epithelia. However, the regulation of stromal AR expression may not be carried out by the same mechanism operating in the epithelia. This notion is supported by the observation that stromal AR expression progressively decreases during malignant transformation, differing from the increased AR expression in the malignant epithelia (Singh et al. 2014). In addition, the differential expression of AR-associated coregulators or transcription factors between stromal and epithelial cells may also cause the differences in their regulatory mechanisms of AR function. For example, AR cofactor ARA55 is only found in stromal cells, whereas AR-associated transcription factor Foxa1 is only expressed in epithelial cells (Mirosevich et al. 2005, Heitzer \& DeFranco 2007). In this study, our molecularly researches were conducted by PCa cell lines which are derived from epithelial cells. Thus, we only concluded our findings to demonstrate the regulatory mechanism of AR expression in prostate epithelial cells.

Results from our statistical analyses showed the significant correlation between PYK2 and nuclear AR expression in PCa tumors, suggesting that PYK2 expression may be associated with AR activation. This notion was further supported by the observations that PYK2 expression or its catalytic activity was critical for AR expression, S81 phosphorylation, or PSA production in benign and malignant prostate cell lines. Importantly, PYK2 can promote AR activity in an androgenindependent manner. Similarly, compared with LNCaP C-33 cells expressing a low level of PYK2, LNCaP C-81 cells containing high PYK2 expression exhibit an elevated level of secreted PSA and a rapid growth rate under an androgen-depleted condition (Lee et al. 2003, Yuan et al. 2007). Although our data suggested the oncogenic role of PYK2 in promoting AR function and PCa cell growth, a previous study showed the inhibitory role of PYK2 in suppressing AR activity in PCa cells by phosphorylating ARA55 (Wang et al. 2002). Nevertheless, it should be emphasized that ARA55 is a stroma-specific AR coactivator and does not express in the epithelia, even in prostate tumors (Li et al. 2002, Heitzer \& DeFranco 2007). In addition, most experiments in that study were done by using AR-null cells, including PC-3 and DU145 cells. It should be noted that nearly all PCa cells express 
functional AR regardless of clinical stage or hormone status (Heinlein \& Chang 2004), indicating the clinical relevance of using endogenous AR-expressing PCa cells. Thus, our in vitro data supported by the clinical observation suggested the oncogenic role of PYK2 in modulating AR activity and growth property in PCa cells. However, PYK2 may also promote cell survival in addition to activating AR function in PCa cells. This notion is supported by the observation that PF-431396 treatment or PYK2 ablation in PCa cells caused an increasing number of round cells floating in the culture medium. A recent study also showed that PYK2 inhibition or knockdown induces cell death in myeloma cells (Meads et al. 2016). Although the further investigation is needed, the ablation of PYK2 expression or activity may lead to apoptosis, in addition to decreased AR function and growth arrest.

In this study, we first reported that S6K1 expression was associated with AR activity and PCa cell growth. Importantly, S6K1 was required for PYK2-regulated AR function. Despite no report so far showing the mechanism of how PYK2 regulates S6K1 activity, it is known that PYK2 via the activation of PI3K signaling promotes mTOR activity (Chapman et al. 2015) and, thus, leads to S6K1 activation. However, an interesting question is how S6K1 regulates AR function. Accumulated evidence indicated the crucial role of S81 phosphorylation in AR nuclear translocation and transcriptional activation (Koryakina et al. 2014). S81 phosphorylation also enhances AR protein stability, correlating with increased protein expression. Previous studies have shown that manipulation of CDK1 or CDK5 expression regulates $\mathrm{S} 81$ phosphorylation and AR expression (Chen et al. 2006, Hsu et al. 2011). In addition, the increase in AR level was paralleled by a decrease in AR ubiquitination. Similarly, our data indicated that PYK2 via S6K1 regulated S81 phosphorylation and AR protein expression. Results from the treatment of $\mathrm{CHX}$ or MG132 further suggested the role of PYK2 in regulating AR stability. Thus, it is possible that PYK2 via S6K1 directly phosphorylates AR at S81 and causes its nuclear localization. Nuclear retention of AR keeps itself away from protein degradation machinery, which leads to AR protein stabilization. Alternatively, S6K1 may regulate S81 phosphorylation indirectly by the inhibition of protein phosphatase 2A (PP2A). It has been showed that inhibition of PP2A in PCa cells promotes S81 phosphorylation and androgen-independent AR activation (Bhardwaj et al. 2011). Furthermore, S6K1 can interact with PP2A and inhibition of mTOR/S6K1 signaling can activate PP2A phosphatase activity (Westphal et al. 1999, Liu et al. 2010). Thus, S6K1 may enhance S81 phosphorylation by binding PP2A and inhibiting its phosphatase activity. Interestingly, S6K1 can also interact with $\mathrm{Mdm} 2$ in the cytoplasm, thus inhibiting Mdm2 nuclear translocation and p53 degradation (Lai et al. 2010). Because Mdm2 functions as an AR-targeted ubiquitin ligase for promoting AR degradation (Lin et al. 2002), whether S6K1-promoted AR stability is mediated by inhibiting Mdm2 function requires further investigation.

In summary, we have demonstrated that the expression of PYK2 and S6K1 in PCa tumors and their levels were significantly correlated with nuclear AR expression. We further showed that PYK2 could modulate AR expression, S81 phosphorylation, PSA production, and PCa cell proliferation in an androgen-deprived condition. Importantly, PYK2-promoted AR functions were mediated by a S6K1-dependent pathway. Thus, our data suggested that PYK2 and S6K1 could serve as therapeutic targets for the treatment of PCa.

\section{Declaration of interest}

The authors declare that there is no conflict of interest that could be perceived as prejudicing the impartiality of the research reported.

\section{Funding}

This work was supported by a grant from the Taiwan National Science Council (NSC 99-2320-B-259-001-MY3 and NSC-102-2314-B-259-001).

\section{References}

Avraham H, Park SY, Schinkmann K \& Avraham S 2000 RAFTK/Pyk2mediated cellular signalling. Cellular Signalling 12 123-133. (doi:10.1016/S0898-6568(99)00076-5)

Ballantyne RM \& McHenry EW 1949 Vitamin B6 and biotin in human cancer tissue. Cancer Research 9 689-691.

Barlund M, Forozan F, Kononen J, Bubendorf L, Chen Y, Bittner ML, Torhorst J, Haas P, Bucher C, Sauter G, et al. 2000 Detecting activation of ribosomal protein $\mathrm{S} 6$ kinase by complementary DNA and tissue microarray analysis. Journal of the National Cancer Institute 92 1252-1259. (doi:10.1093/jnci/92.15.1252)

Behmoaram E, Bijian K, Jie S, Xu Y, Darnel A, Bismar TA \& AlaouiJamali MA 2008 Focal adhesion kinase-related proline-rich tyrosine kinase 2 and focal adhesion kinase are co-overexpressed in earlystage and invasive ErbB-2-positive breast cancer and cooperate for breast cancer cell tumorigenesis and invasiveness. American Journal of Pathology 173 1540-1550. (doi:10.2353/ajpath.2008.080292)

Bhardwaj A, Singh S, Srivastava SK, Honkanen RE, Reed E \& Singh AP 2011 Modulation of protein phosphatase $2 \mathrm{~A}$ activity alters androgenindependent growth of prostate cancer cells: therapeutic implications. Molecular Cancer Therapeutics 10 720-731. (doi:10.1158/1535-7163.MCT-10-1096)

Buckbinder L, Crawford DT, Qi H, Ke HZ, Olson LM, Long KR, Bonnette PC, Baumann AP, Hambor JE, Grasser WA 3rd, et al. 2007 Proline-rich tyrosine kinase 2 regulates osteoprogenitor cells and bone formation, and offers an anabolic treatment approach for osteoporosis. PNAS 104 10619-10624. (doi:10.1073/ pnas.0701421104) 
Chakraborty S, Mohiyuddin SM, Gopinath KS \& Kumar A 2008 Involvement of TSC genes and differential expression of other members of the mTOR signaling pathway in oral squamous cell carcinoma. BMC Cancer 8 163. (doi:10.1186/1471-2407-8-163)

Chang YL, Hsu YK, Wu TF, Huang CM, Liou LY, Chiu YW, Hsiao YH, Luo FJ \& Yuan TC 2014 Regulation of estrogen receptor alpha function in oral squamous cell carcinoma cells by FAK signaling. Endocrine-Related Cancer 21 555-565. (doi:10.1530/ERC-14-0102)

Chapman NM, Yoder AN, Barbon KM, Bilal MY, Connolly SF \& Houtman JC 2015 Proline-rich tyrosine kinase 2 controls PI3-kinase activation downstream of the $\mathrm{T}$ cell antigen receptor in human $\mathrm{T}$ cells. Journal of Leukocyte Biology 97 285-296. (doi:10.1189/ jlb.2A1013-568RRR)

Chen S, Xu Y, Yuan X, Bubley GJ \& Balk SP 2006 Androgen receptor phosphorylation and stabilization in prostate cancer by cyclindependent kinase 1. PNAS 103 15969-15974. (doi:10.1073/ pnas.0604193103)

Chen S, Gulla S, Cai C \& Balk SP 2012 Androgen receptor serine 81 phosphorylation mediates chromatin binding and transcriptional activation. Journal of Biological Chemistry 287 8571-8583. (doi:10.1074/jbc.M111.325290)

Couch FJ, Wang XY, Wu GJ, Qian J, Jenkins RB \& James CD 1999 Localization of PS6K to chromosomal region 17q23 and determination of its amplification in breast cancer. Cancer Research 59 1408-1411.

Crawford ED, Rosenblum M, Ziada AM \& Lange PH 1999 Hormone refractory prostate cancer. Urology 54 1-7. (doi:10.1016/S00904295(99)00447-1)

Devlin HL \& Mudryj M 2009 Progression of prostate cancer: multiple pathways to androgen independence. Cancer Letters 274 177-186. (doi:10.1016/j.canlet.2008.06.007)

Dikic I, Tokiwa G, Lev S, Courtneidge SA \& Schlessinger J 1996 A role for Pyk2 and Src in linking G-protein-coupled receptors with MAP kinase activation. Nature 383 547-550. (doi:10.1038/383547a0)

Evren S, Dermen A, Lockwood G, Fleshner N \& Sweet J 2010 Immunohistochemical examination of the mTORC1 pathway in high grade prostatic intraepithelial neoplasia (HGPIN) and prostatic adenocarcinomas (PCa): a tissue microarray study (TMA). Prostate 70 1429-1436. (doi:10.1002/pros.21178)

Fahmy N, Woo M, Alameldin M, Lee JK, MacDonald K, Goneau LW, Cadieux P, Burton J \& Pautler S 2014 Endogenous biotin expression in renal and testicular tumours and literature review. Canadian Urological Association Journal 8 268-272. (doi:10.5489/cuaj.1810)

Fenton TR \& Gout IT 2011 Functions and regulation of the 70kDa ribosomal S6 kinases. International Journal of Biochemistry and Cell Biology 43 47-59. (doi:10.1016/j.biocel.2010.09.018)

Fingar DC \& Blenis J 2004 Target of rapamycin (TOR): an integrator of nutrient and growth factor signals and coordinator of cell growth and cell cycle progression. Oncogene 23 3151-3171. (doi:10.1038/ sj.onc.1207542)

Genua M, Xu SQ, Buraschi S, Peiper SC, Gomella LG, Belfiore A, Iozzo RV \& Morrione A 2012 Proline-rich tyrosine kinase 2 (Pyk2) regulates IGF-I-induced cell motility and invasion of urothelial carcinoma cells. PLOS ONE 7 e40148. (doi:10.1371/journal. pone.0040148)

Gioeli D, Ficarro SB, Kwiek JJ, Aaronson D, Hancock M, Catling AD, White FM, Christian RE, Settlage RE, Shabanowitz J, et al. 2002 Androgen receptor phosphorylation. Regulation and identification of the phosphorylation sites. Journal of Biological Chemistry 277 29304-29314. (doi:10.1074/jbc.M204131200)

Gordon V, Bhadel S, Wunderlich W, Zhang J, Ficarro SB, Mollah SA, Shabanowitz J, Hunt DF, Xenarios I, Hahn WC, et al. 2010 CDK9 regulates $\mathrm{AR}$ promoter selectivity and cell growth through serine 81 phosphorylation. Molecular Endocrinology 24 2267-2280. (doi:10.1210/me.2010-0238)
Grossmann ME, Huang H \& Tindall DJ 2001 Androgen receptor signaling in androgen-refractory prostate cancer. Journal of the National Cancer Institute 93 1687-1697. (doi:10.1093/jnci/93.22.1687)

Heinlein CA \& Chang C 2004 Androgen receptor in prostate cancer. Endocrine Reviews 25 276-308. (doi:10.1210/er.2002-0032)

Heitzer MD \& DeFranco DB 2007 Hic-5/ARA55: a prostate stromaspecific AR coactivator. Steroids 72 218-220. (doi:10.1016/j. steroids.2006.11.010)

Hsu FN, Chen MC, Chiang MC, Lin E, Lee YT, Huang PH, Lee GS \& Lin H 2011 Regulation of androgen receptor and prostate cancer growth by cyclin-dependent kinase 5. Journal of Biological Chemistry 286 33141-33149. (doi:10.1074/jbc.M111.252080)

Iiizumi M, Bandyopadhyay S, Pai SK, Watabe M, Hirota S, Hosobe S, Tsukada T, Miura K, Saito K, Furuta E, et al. 2008 RhoC promotes metastasis via activation of the Pyk2 pathway in prostate cancer. Cancer Research 68 7613-7620. (doi:10.1158/0008-5472.CAN-076700)

Jeno P, Ballou LM, Novak-Hofer I \& Thomas G 1988 Identification and characterization of a mitogen-activated S6 kinase. PNAS 85 406-410. (doi:10.1073/pnas.85.2.406)

Kimura N, Mizokami A, Oonuma T, Sasano H \& Nagura H 1993 Immunocytochemical localization of androgen receptor with polyclonal antibody in paraffin-embedded human tissues. Journal of Histochemistry and Cytochemistry 41 671-678. (doi:10.1177/41.5.8468448)

Koryakina Y, Ta HQ \& Gioeli D 2014 Androgen receptor phosphorylation: biological context and functional consequences. Endocrine-Related Cancer 21 T131-145. (doi:10.1530/erc-13-0472)

Lai KP, Leong WF, Chau JF, Jia D, Zeng L, Liu H, He L, Hao A, Zhang H, Meek D, et al. 2010 S6K1 is a multifaceted regulator of Mdm2 that connects nutrient status and DNA damage response. EMBO Journal 29 2994-3006. (doi:10.1038/emboj.2010.166)

Lee MS, Igawa T, Yuan TC, Zhang XQ, Lin FF \& Lin MF 2003 ErbB-2 signaling is involved in regulating PSA secretion in androgenindependent human prostate cancer LNCaP C-81 cells. Oncogene 22 781-796. (doi:10.1038/sj.onc.1206066)

Lev S, Moreno H, Martinez R, Canoll P, Peles E, Musacchio JM, Plowman GD, Rudy B \& Schlessinger J 1995 Protein tyrosine kinase PYK2 involved in $\mathrm{Ca}(2+)$-induced regulation of ion channel and MAP kinase functions. Nature 376 737-745. (doi:10.1038/376737a0)

Li X, Dy RC, Cance WG, Graves LM \& Earp HS 1999 Interactions between two cytoskeleton-associated tyrosine kinases: calciumdependent tyrosine kinase and focal adhesion tyrosine kinase. Journal of Biological Chemistry 274 8917-8924. (doi:10.1074/ jbc.274.13.8917)

Li X, Kimbrel EA, Kenan DJ \& McDonnell DP 2002 Direct interactions between corepressors and coactivators permit the integration of nuclear receptor-mediated repression and activation. Molecular Endocrinology 16 1482-1491. (doi:10.1210/mend.16.7.0860)

Lin HK, Wang L, Hu YC, Altuwaijri S \& Chang C 2002 Phosphorylationdependent ubiquitylation and degradation of androgen receptor by Akt require Mdm2 E3 ligase. EMBO Journal 21 4037-4048. (doi:10.1093/emboj/cdf406)

Lipinski CA, Tran NL, Menashi E, Rohl C, Kloss J, Bay RC, Berens ME \& Loftus JC 2005 The tyrosine kinase pyk2 promotes migration and invasion of glioma cells. Neoplasia 7 435-445. (doi:10.1593/ neo.04712)

Liu L, Chen L, Luo Y, Chen W, Zhou H, Xu B, Han X, Shen T \& Huang S 2010 Rapamycin inhibits IGF-1 stimulated cell motility through PP2A pathway. PLOS ONE 5 e10578. (doi:10.1371/journal. pone.0010578)

Meads MB, Fang B, Mathews L, Gemmer J, Nong L, Rosado-Lopez I, Nguyen T, Ring JE, Matsui W, MacLeod AR, et al. 2016 Targeting PYK2 mediates microenvironment-specific cell death in multiple myeloma. Oncogene 35 2723-2734. (doi:10.1038/onc.2015.334) http://erc.endocrinology-journals.org

DOI: 10.1530/ERC-16-0122
(C) 2016 Society for Endocrinology Printed in Great Britain
Published by Bioscientifica Ltd 
Mirosevich J, Gao N \& Matusik RJ 2005 Expression of Foxa transcription factors in the developing and adult murine prostate. Prostate $\mathbf{6 2}$ 339-352. (doi:10.1002/pros.20131)

Mitra SK, Hanson DA \& Schlaepfer DD 2005 Focal adhesion kinase: in command and control of cell motility. Nature Reviews Molecular Cell Biology 6 56-68. (doi:10.1038/nrm1549)

Saitoh M, Pullen N, Brennan P, Cantrell D, Dennis PB \& Thomas G 2002 Regulation of an activated S6 kinase 1 variant reveals a novel mammalian target of rapamycin phosphorylation site. Journal of Biological Chemistry 277 20104-20112. (doi:10.1074/jbc.M201745200)

Singh M, Jha R, Melamed J, Shapiro E, Hayward SW \& Lee P 2014 Stromal androgen receptor in prostate development and cancer. American Journal of Pathology 184 2598-2607. (doi:10.1016/j.ajpath.2014.06.022)

Stanzione R, Picascia A, Chieffi P, Imbimbo C, Palmieri A, Mirone V, Staibano S, Franco R, De Rosa G, Schlessinger J, et al. 2001 Variations of proline-rich kinase Pyk2 expression correlate with prostate cancer progression. Laboratory Investigation 81 51-59. (doi:10.1038/ labinvest.3780211)

Sun CK, Ng KT, Sun BS, Ho JW, Lee TK, Ng I, Poon RT, Lo CM, Liu CL, Man K, et al. 2007 The significance of proline-rich tyrosine kinase2 (Pyk2) on hepatocellular carcinoma progression and recurrence. British Journal of Cancer 97 50-57. (doi:10.1038/sj.bjc.6603827)

Sun CK, Man K, Ng KT, Ho JW, Lim ZX, Cheng Q, Lo CM, Poon RT \& Fan ST 2008 Proline-rich tyrosine kinase 2 (Pyk2) promotes proliferation and invasiveness of hepatocellular carcinoma cells through c-Src/ERK activation. Carcinogenesis 29 2096-2105. (doi:10.1093/carcin/bgn203)

Tokiwa G, Dikic I, Lev S \& Schlessinger J 1996 Activation of Pyk2 by stress signals and coupling with JNK signaling pathway. Science $\mathbf{2 7 3}$ 792-794. (doi:10.1126/science.273.5276.792)
Wang X, Yang Y, Guo X, Sampson ER, Hsu CL, Tsai MY, Yeh S, Wu G, Guo Y \& Chang C 2002 Suppression of androgen receptor transactivation by Pyk2 via interaction and phosphorylation of the ARA55 coregulator. Journal of Biological Chemistry 277 15426-15431. (doi:10.1074/jbc.M111218200)

Westphal RS, Coffee RL Jr, Marotta A, Pelech SL \& Wadzinski BE 1999 Identification of kinase-phosphatase signaling modules composed of p70 S6 kinase-protein phosphatase 2A (PP2A) and p21-activated kinase-PP2A. Journal of Biological Chemistry 274 687-692. (doi:10.1074/jbc.274.2.687)

Yamnik RL, Digilova A, Davis DC, Brodt ZN, Murphy CJ \& Holz MK 2009 S6 kinase 1 regulates estrogen receptor alpha in control of breast cancer cell proliferation. Journal of Biological Chemistry 284 6361-6369. (doi:10.1074/jbc.M807532200)

Yuan TC, Lin FF, Veeramani S, Chen SJ, Earp HS 3rd \& Lin MF 2007 ErbB-2 via PYK2 upregulates the adhesive ability of androgen receptor-positive human prostate cancer cells. Oncogene $\mathbf{2 6}$ 7552-7559. (doi:10.1038/sj.onc.1210570)

Zhang S, Qiu X, Gu Y \& Wang E 2008 Up-regulation of proline-rich tyrosine kinase 2 in non-small cell lung cancer. Lung Cancer 62 295-301. (doi:10.1016/j.lungcan.2008.05.008)

Zhang Y, Moschetta M, Huynh D, Tai YT, Zhang Y, Zhang W, Mishima Y, Ring JE, Tam WF, Xu Q, et al. 2014 Pyk2 promotes tumor progression in multiple myeloma. Blood 124 2675-2686. (doi:10.1182/blood-2014-03-563981)

Zrihan-Licht S, Fu Y, Settleman J, Schinkmann K, Shaw L, Keydar I, Avraham S \& Avraham H 2000 RAFTK/Pyk2 tyrosine kinase mediates the association of p190 RhoGAP with RasGAP and is involved in breast cancer cell invasion. Oncogene 19 1318-1328. (doi:10.1038/ sj.onc.1203422)

Received in final form 27 June 2016

Accepted 30 June 2016
(C) 2016 Society for Endocrinology Printed in Great Britain
Published by Bioscientifica Ltd 